\title{
HEALTH IN THE 1980's
}

How will health and medical practice have developed by the end of the 1980's? This question was examined by a score of participants in the meeting organized jointly by the Henry Dunant Institute and Messrs Sandoz S.A. and held in Basle from 13 to 15 September 1972.

The meeting was, in fact, the final phase of an enquiry, among some sixty eminent persons in eighteen countries, on Health and Medical Practice in the 1980's, with a view to educing a number of results which were descried during the enquiry itself and which were mentioned in the August issue of International Review.

During the three working days, the participants endeavoured to define what would be the health problems arising in the advanced countries and what would be the likely solutions. They also tried to forecast what workers and means would be required to meet needs, with special reference to the so-called " civilization " diseases (cancerous, cardiac, mental). The functions of the para-medical professions (nurses, medical assistants, etc.) and the work of public institutions were central to the proceedings, as were also questions of public information and hygiene education.

This was the first full enquiry of this kind on an international scale. The results will shortly be published, but in the meantime we would underline here the considerable interest of such a meeting to the Red Cross which, in fact, has been working for over a century to improve health and prevent disease. The Red Cross activities in this field are manifold (especially in relation to medical personnel and hospitals) and it is well qualified to educate the public in matters of health. In addition, such meetings, by systematically capitalizing on information of the greatest interest, should permit the Red Cross to predict its role in the world of tomorrow and to prepare accordingly in good time. 
As Mr. Jean Pictet, Vice-President of the International Committee of the Red Cross, stated during the closing session:

...By proposing, in 1864, the conclusion of the first Geneva Convention, the International Committee of the Red Cross obtained protection for military doctors even on the battlefield, and even when wearing military uniform, by reason of their healing mission. And it was thus that the red cross on a white background, instituted by the movement's founders, became the emblem of the medical service's immunity from attack, as well as our institution's flag.

A type of co-operation which has been not only ceaseless but considerably developed dates from that time; the Red Cross soon outgrew its narrow limits, wishing no longer to restrict its concern to war victims but to extend it to nature's victims, the sick, the disabled, the weak.

So the Red Cross became inseparably associated with medicine, the noblest of all professions. The Red Cross and medicine have a common aim: to struggle against suffering and death. They also have a common ethic, for your deontology coincides with our principles, and a common capital precept of non-discrimination which does not date back to Hippocrates but is a great conquest of modern times and which, as J.- G. Lossier wrote, has enabled the two worlds of master and servant to come together to form a single humanity.

Today, the doctor's mission, like that of the Red Cross worker, is increasingly difficult, for our times are convulsed by phenomena such as the demographic explosion, the technological revolution, the clash of profoundly differing ideologies and the world-shaking emergence of new forces. The result is a hardening of hearts, a laxity in morals and a terrible resurgence of violence. Suffering itself has become a political weapon, an abundant source of propaganda, to such an extent indeed that the Red Cross is sometimes taken to task for putting a stop to it! All too often powerless, we witness aghast this rising tide of neobarbarity.

It must therefore be realized that the giving of succour requires more and more courage. To be true to one's duty today, in an increasingly fanatical and implacable world, may involve risking one's life. The doctor has to be prepared to face the risk. His mission requires also a profound inner preparation. Henceforth, confronted with new and 
unsuspected phenomena, he must, to survive and to adapt, acquire new personal qualities and assert new ethical standards. And it is in that context that your work is significant...

To bring the action of the Red Cross up to date and assess its possibilities for development in tomorrow's world, such were the reasons which induced the League of Red Cross Societies and the International Committee of the Red Cross to assign to the Henry Dunant Institute the investigation of which the meeting in Basle was the final phase. That, however, was only the first stage. Other meetings will follow which, it is hoped, will make it possible to define both the possibilities and the limits of humanitarian action in a rapidly changing world.

\section{RED CROSS INFORMATION MEETING}

In response to a joint invitation from the International Committee of the Red Cross and the League of Red Cross Societies, some twenty experts from different National Red Cross Societies met in Geneva, on 3 November 1972, to hear reports on current Red Cross programmes in Indochina and on those being prepared.

The Red Cross experts considered the various possibilities for increased humanitarian action following a cease-fire in that part of the world, with the agreement of the local authorities and of the Red Cross bodies directly responsible. Pending such a cease-fire, the Red Cross regards it as imperative to reinforce its current programmes so that it may be able to fulfil its traditional tasks on a larger scale. 